Japanese Journal of Physiology, 32, 309-313, 1982

\title{
Responses of Salivatory Neurons in the Medulla Oblongata of Rabbit
}

\author{
Ryuji Matsuo, Takashi Yamamoto, and Yojiro Kawamura \\ Department of Oral Physiology, Dental School, Osaka University, \\ Kitaku, Osaka, 530 Japan
}

Summary Extracellular antidromic and orthodromic responses of the salivatory neurons in the medulla oblongata which send preganglionic parasympathetic fibers to the submandibular gland were recorded in rabbits. The mean of conduction time from the subnucleus caudalis of the spinal trigeminal nucleus to the salivatory neurons was within a range of 4.8-6.4 msec, suggesting oligosynaptic but not monosynaptic connections between the first order trigeminal sensory nucleus and the salivatory neurons.

Key Words: salivatory neuron, reflex, antidromic response.

In our recent studies (KaWAMURA and Yamamoto, 1978; KawAmura et al., 1982; MATSuO et al., 1980b, 1981; Yамамото and KawAMURA, 1977a, b), the reflex activities of the preganglionic parasympathetic fibers (axons of the salivatory neurons) innervating the submandibular gland were recorded in rabbits, and some response characteristics of these neurons were evaluated. However, the nature of central synaptic linkages between afferent inputs and salivatory neuronal outputs has not yet been properly determined.

Gustatory stimuli elicited neural responses in the preganglionic parasympathetic fibers with long latencies (KaWAMURA and YамAMOTO, 1978; Yамамото and KAWAMURA, 1977a, b), the reflex salivation being very susceptible to systemic anesthesia (RoBBINS, 1935). These findings suggest that a polysynaptic rather than monosynaptic linkage exists between the first order sensory nucleus and the salivatory nucleus in the brainstem. On the other hand, neuronanatomical studies (Norgren, 1976, 1978; Norgren and ConTrERAS, 1979) suggest the possibility of a mono- or di-synaptic arc underlying the gustatory-salivary reflexes.

Therefore, in the present study, neuronal activities of the salivatory neurons and the spinal trigeminal sensory nuclei induced by electrical stimulation of the oral region were recorded to elucidate the nature of the salivary reflex arc.

Sixteen rabbits (2.0-3.6 kg body weight) of either sex were used. They were

Received for publication September 4, 1981

松尾龍二, 山本 隆, 河村洋二郎 
anesthetized by intravenous injection of $\alpha$-chloralose $(50 \mathrm{mg} / \mathrm{kg})$ and urethane $(500 \mathrm{mg} / \mathrm{kg})$. After the head was fixed on a stereotaxic apparatus, the cerebellum was removed and the dorsal surface of the medulla was exposed. The surface was covered with warm mineral oil. Platinum-iridium wire was used for the recording microelectrode (3-5 $\mu \mathrm{m}$ in tip diameter, insulated except for the tip), and it was inserted into the medulla by a microdrive manipulator. At the end of the experiment, the brain tissue was electrically coagulated by passing currents through the recording electrode $(20 \mu \mathrm{A}, 20 \mathrm{sec})$ and the location of the tip of the microelectrode was later verified histologically.

For antidromic activation of salivatory neurons, a sleeve-type stimulating electrode ( $3 \mathrm{~mm}$ interpolar distance) was attached to the preganglionic fibers near the duct of the submandibular gland. The electrical stimulation was applied to the fibers with rectangular pulses of $0.1 \mathrm{msec}$ duration and $3 \mathrm{~mA}$ intensity at 1-100 Hz.

The upper lip, anterior part of the palate, anterior part of the tongue and lower lip were electrically stimulated $(0.1 \mathrm{msec}$ duration, $6 \mathrm{~mA}$ intensity, 1-100 $\mathrm{Hz})$ by pairs of stainless-steel wire electrodes $(200 \mu \mathrm{m}$ in diameter, insulated except for the cut tip, 2-3 $\mathrm{mm}$ interpolar distance), and the induced reflex activities of the salivatory neurons were examined.

Thirteen salivatory neurons were identified according to the following criteria. 1) The location of the sampled neurons was within the distribution of salivatory neurons revealed by a previous anatomical study (MATSuo et al., 1980a). 2) The all-or-none responses were evoked by stimulation applied to the preganglionic fibers with a constant latency following repetitive stimulation rates (antidromic responses). 3) The reflex activities were evoked by electrical stimulation applied to the ipsilateral oral regions (orthodromic responses).

An example of the neuronal activity is shown in Fig. 1-A. This neuron showed an all-or-none response (Fig. 1-Aa) with little variation of latency (4.6 msec) (Fig. 1-Ab), and it followed $50 \mathrm{~Hz}$ stimulation of the preganglionic fibers. This neuron also responded orthodromically to a shock applied to the upper lip with unstable latencies of around $7.4 \mathrm{msec}$ (Fig. 1-Ac).

All the recorded neurons responded with a constant latency of $4.0 \pm 0.9$ $\operatorname{msec}($ mean \pm S.D., $n=13$ ) to the antidromic stimulation of the preganglionic fibers, and they also showed an orthodromic response to single electrical shocks applied to the ipsilateral oral region with one or more evoked impulses. Out of a total of 13 neurons, 3 responded to electrical stimulation applied to the upper lip, 2 to the anterior part of the palate, 4 to the anterior part of the tongue, and 4 to the lower lip. The mean latency of the orthodromic response was $7.7 \pm 2.3 \mathrm{msec}$ $(n=13)$. The mean latency of the reflex discharges of the preganglionic fibers evoked by a single electrical shock applied to the oral regions was $10.7 \pm 3.2 \mathrm{msec}$ ( $n=64)$ (KAWAMURA et al., 1982). This value well corresponded to the mean value of $11.7 \pm 2.8 \mathrm{msec}(n=13)$ which was the sum of the latency for antidromic 


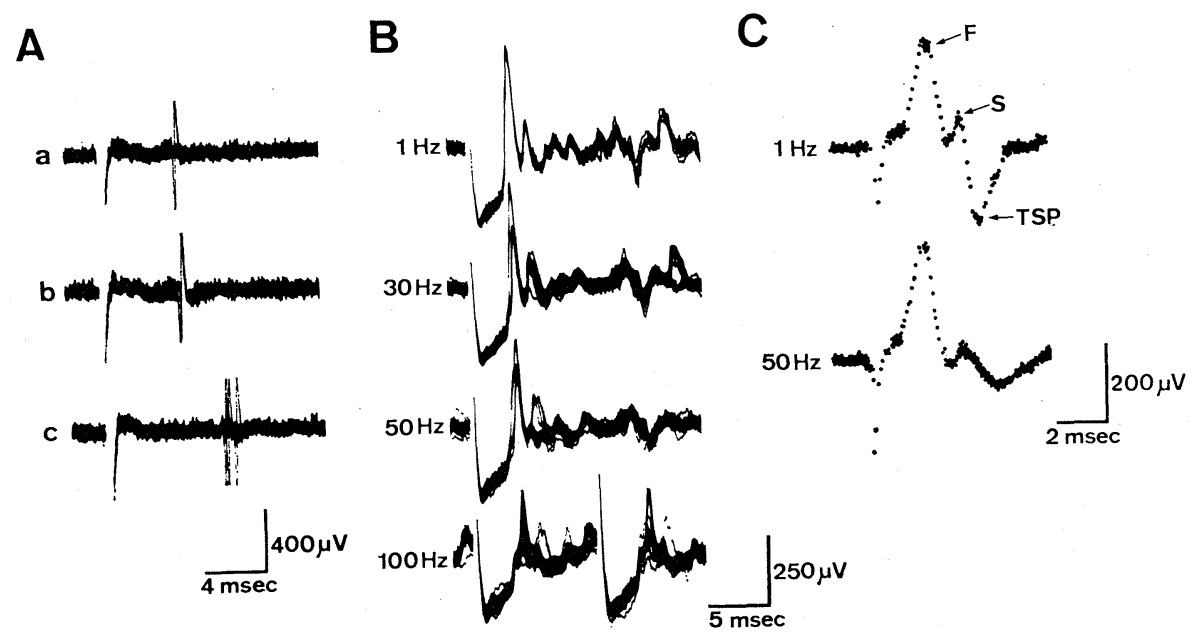

Fig. 1. Antidromic and orthodromic responses recorded from a superior salivatory neuron (A). Aa, superimposed tracings of antidromic spikes at near-threshold intensity; Ab, antidromic spikes at $50-\mathrm{Hz}$ stimulation; Ac, orthodromic responses evoked by electrical stimulation applied to the ipsilateral upper lip. Note the variable and longer latency. Compound action potentials recorded from a fine strand of the preganglionic parasympathetic fibers innervating the submandibular gland (B). Electrical stimulation was applied to the chorda tympani nerve at frequencies of $1,30,50$, and $100 \mathrm{~Hz}$. Evoked potentials recorded from the subnucleus caudalis at the level of obex (C). These potentials were obtained by averaging 50 sweeps evoked by electrical stimulation of the infraorbital nerve at frequencies of 1 and $50 \mathrm{~Hz}$. F, fast component; S, slow component of incoming volley; TSP, trans-synaptic potential.

responses and that for orthodromic responses of the salivatory neurons.

The salivatory neurons were unable to respond faithfully to high frequencies of antidromic stimulation, i.e., the following capacities of 13 neurons were within the range of $50-100 \mathrm{~Hz}$. This phenomenon may suggest that their axons (the preganglionic fibers) are small in diameter. To elucidate the low following capacities of these axons, electrophysiological properties of the preganglionic parasympathetic fibers per se were examined in several animals. The chorda tympani nerve which contains the preganglionic parasympathetic fibers was stimulated $(0.1 \mathrm{msec}$ duration, $2 \mathrm{~mA}$ intensity, $1-100 \mathrm{~Hz})$ with a pair of platinum wire electodes $(2 \mathrm{~mm}$ interpolar distance), and the induced impulses were recorded distally from a fine strand of preganglionic fiber near the duct by a monopolar platinum wire electrode (100 $\mu \mathrm{m}$ in diameter). Typical records are shown in Fig. 1-B. In this figure, among the several action potentials with varying amplitudes and latencies observed by stimulation at $1 \mathrm{~Hz}$, slowly conducted ones disappeared first at $50 \mathrm{~Hz}$, followed by some faster conducted ones with an increase of the stimulus frequency up to $100 \mathrm{~Hz}$. From such recordings, it was also found that the conduction 
velocity of preganglionic fibers ranged from 2.3 to $11.3 \mathrm{~m} / \mathrm{sec}$. These values correspond well to the conduction rates of $4-11 \mathrm{~m} / \mathrm{sec}$ measured in the preganglionic parasympathetic fibers innervating the submandibular gland in dogs (IRIUCHIJMA and ZotTERMAN, 1961).

In the next step, we estimated the conduction time in the brain by subtracting the latency of sensory responses in the trigeminal sensory nucleus from the latency of orthodromic responses of salivatory neurons. It is suggested that the subnucleus caudalis of the spinal trigeminal nucleus plays an important role in reflex salivation, since the volume of salivation induced by stimulation of the trigeminal region was largely diminished after tractotomy at the level of the obex (KAWAMURA and Yамамото, 1977). Therefore, potentials evoked in response to electrical stimulation of the infraorbital nerve were recorded from the subnucleus caudalis with a silver ball electrode $(0.5 \mathrm{~mm}$ in diameter $)$ placed on the surface of the medulla at the level of obex. An example of such evoked potentials is shown in Fig. 1-C, where each recording shows a 50-averaged potential consisting of 3 components; F, S, and TSP, as indicated in the figure. Since F and S components followed repetitive shocks at frequencies over $100 \mathrm{~Hz}, \mathrm{~F}$ and $\mathrm{S}$ components may reflect incoming afferent inputs via fast conducting fibers and slowly conducting fibers, respectively. The following third component (TSP) indicates transsynaptic potentials, because the magnitude of this component decreased greatly at frequencies over $50 \mathrm{~Hz}$, as shown in the figure. The mean latencies of the onsets of $\mathrm{F}$ and $\mathrm{S}$ components obtained in 4 experiments were 1.3 and $2.9 \mathrm{msec}$, respectively. By subtracting these mean values from the mean latency $(7.7 \mathrm{msec})$ of orthodromic responses of salivatory neurons, the mean time of conduction taken in the brain was found to range from 4.8 to $6.4 \mathrm{msec}$. These values may imply that oligosynaptic, rather than monosynaptic, connections exist between the trigeminal sensory nuclei and the salivatory neurons. This possibility may be supported, at least in part, by the following previous observations; 1) The optimum frequency of electrical stimulation applied to the oral-facial region is as low as $10-20 \mathrm{~Hz}$ for inducing the most dominant impulse discharges in the preganglionic parasympathetic fibers (KAWAMURA et al., 1982; MATSUO et al., 1980b, 1981) and 2) about one-third of the preganglionic fibers showed decreases in their spontaneous firing rates following repetitive electrical stimulation of the trigeminal region (KAWAMURA et al., 1982), indicating the existence of inhibitory interneurons.

This study was supported in part by a Grant-in-Aid for Scientific Research (No. 457458) from the Ministry of Education, Science and Culture of Japan.

\section{REFERENCES}

IrIUCHIJIMA, J. and ZotTerman, Y. (1961) Conduction rates of afferent fibers to the anterior tongue of the dog. Acta Physiol. Scand., 51: 283-289.

Kawamura, Y., Matsuo, R., and Yamamoto, T. (1982) Analysis of reflex responses in pre- 
ganglionic parasympathetic fibers innervating submandibular glands of rabbits. J. Physiol. (Lond.), 322: 241-255.

KaWAmuRA, Y. and Yамамото, T. (1977) Salivary secretion to noxious stimulation of the trigeminal area. In: Pain in the Trigeminal Region, ed. by ANDERson, D. J. and MAtThews, B. Elsevier, Amsterdam, pp. 395-404.

Kawamura, Y. and Yамамото, T. (1978) Studies on neural mechanisms of the gustatory-salivary reflex in rabbits. J. Physiol. (Lond.), 285: 35-47.

Matsuo, R., Yамамото, T., and Kawamura, Y. (1980a) Morphological and functional evaluation of the superior salivatory nucleus in rabbits. Exp. Neurol., 68: 147-157.

Matsuo, R., Yamamoto, T., and Kawamura, Y. (1980b) Reflex activation of the preganglionic fibers innervating the submandibular gland. J. Dent. Res. (Spec. Issue B), 59: 929.

Matsuo, R., Yamamoto, T., and Kawamura, Y. (1981) Reflex activation of the preganglionic fibers innervating the submandibular gland. In: Saliva and Salivation, ed. by Zelles, T. Pergamon Press, New York, pp. 11-16.

Norgren, R. (1976) Taste pathways to hypothalamus and amygdala. J. Comp. Neurol., 166: $17-30$.

Norgren, R. (1978) Projections from the nucleus of the solitary tract in the rat. Neuroscience, 3: $207-218$.

Norgren, R. and Contreras, R. J. (1979) The anatomical basis for salivatory responses to gustatory stimuli. Proceedings of the 13th Japanese Symposium on Taste and Smell, held at Gifu, Japan, pp. 5-10.

RobBins, B. H. (1935) Effect of various anesthetics on salivary secretion. J. Pharmacol. Exp. Ther., 54: 426-432.

YAmAmoto, T. and Kawamura, Y. (1977a) Gustatory-salivary reflex in the rabbit. In: Food Intake and Chemical Senses, ed. by Katsuki, Y., SAto, M., Takagi, S. F., and Oomura, Y. Tokyo Univ. Press, Tokyo, pp. 211-221.

YAMAMOTO, T. and KaWAMURA, Y. (1977b) Responses of the submandibular secretory nerve to taste stimuli. Brain Res., 130: 152-155. 